\title{
HIGH MOUNTAIN COMMUNITY IN A CHANGING CLIMATE: A STUDY OF AGROPASTORAL ADAPTATION IN MUSTANG DISTRICT, NEPAL
}

\author{
Prakash Upadhyay \\ Tribhuvan University, Prithvi Narayan Campus, Pokhara, Nepal
}

\begin{abstract}
This paper explores the changing climate, its impact, and the diversified practices of agropastoral adaption by a mountain community of Nepal. The findings reveal that there is an unswerving link between the changes in climate and their impact on the community and its adaptation options. The vulnerability and risk induced by the climate change has threatened the agropastoral subsistence, the sociocultural and economic structure, and the food sovereignty of the Loba community of Mustang district of Nepal and made them experience unanticipated complications in livelihood. In a changing climate, the community has attuned and restructured its adaptive strategy with diversified practices of collective labour in a traditional agropastoral system of landholding, mystical connectivity and seasonal relocation as an adaptive response ensuring the shared sustenance of the community. The challenge of climate change began long ago; it will persevere and be long-lasting. Hence, this paper argues for the need for a prudent adoption of measures to maintain an environmentally suitable agropastoral system of livelihood well-being. Beyond enhancing community capacity and climate resilience, it is necessary to streamline and readjust indigenous sociocultural institutions by expanding their adaptive capacity, while recognizing the cultural dimensions grounded in systems of meanings and relationships and the way people and their culture experience and respond to exceptional climatic changes.
\end{abstract}

Keywords: ethnography; food sovereignty; polyandry; periodic relocation; smart management 


\section{INTRODUCTION}

With the beginning of the industrial revolution in the $18^{\text {th }}$ century, human activities started manipulating the climate of the earth. However, in the $20^{\text {th }}$ century, climate change emerged as a major menace to humankind, which is due to global warming because an increased quantity of the sun's heat striking the earth is being confined in atmosphere. About 25 percent of all plant and animal species on the earth face the threat of extinction with a mere two-degree raise in temperature [18]. Although climate change is not utterly destructive, for the majority of the world's population the negative impacts of global warming on health and agriculture are greater than its benefits [8]. Climate change causes the greatest damage to the most vulnerable populations who lack the capability to cope with and adapt to climate change because of a lack of access to essential resources [23]. Marginalized inhabitants of remote regions like children, women, the elderly, and the impoverished have little access to and control over resources and, hence, are more harshly impacted by climate change [9]. Anthropogenic human activities are increasing the hazards of raising temperature, desertification, soil erosion, deforestation, flooding, storms, and the melting of glaciers in the Himalayas [25]. With escalating temperatures, the runoff peaks shift to winter and early spring, away from summer and autumn when the demand is greatest [2].

Considerable differences and inconsistencies can be perceived between different regions, places and communities, but vulnerability to climate change is expected to be high in remote mountains [10]. Located in south Asia and sandwiched between India and the Tibet Autonomous Region of China, Nepal is a landlocked country along the southern slopes of the Himalayan ranges. Surrounded by high mountains, Nepal is divided into three ecological belts: the hilly region $-68 \%$, the Terai plain $-17 \%$, mountains $-15 \%$. The remote mountain region rises above 3000 meters into the subalpine and alpine zones used for seasonal pasturage, and to the highest peak - Mount Everest (8848 meters) [6]. The biodiversity, ecology and infrastructure of the high mountain region is in continuous threat of destruction due to geophysical and socio-economic conditions, its fragile ecosystem and global warming. The consistent rise in maximum temperature is at an annual rate of $0.04-0.06^{\circ} \mathrm{C}$ [11]. The country is more susceptible to climate change impact due to its limited capacity to cope with climate change hazards [13].

The Mustang district is one of the total 77 districts (an administrative unit) of Nepal. Located in the high mountain region and surrounded by high Himalayan peaks at an elevation ranging from 1,372 to 8,167 meters, the Mustang 
district with an area of 3,573 $\mathrm{km}^{2}$ and a population of 13,452 is bordered by the Tibetan plateau and is one of the most protected, remote and sparsely populated districts of Nepal [5]. The Department of Hydrology and Meteorology (DHM) Mustang Station has reported that the minimum annual average temperature of the Upper Mustang region is escalating at an annual rate of $0.048^{\circ} \mathrm{C}$. Summer temperature is increasing at an annual rate of $0.024{ }^{\circ} \mathrm{C}$ and winter temperature is escalating at a rate of $0.115^{\circ} \mathrm{C}$ annually. Escalation of temperature has threatened the ecosystem and biological behaviour of the flora and the fauna. Melting glaciers, fluctuations in weather patterns, increasing temperature, frequency and intensity of extreme weather events and natural disasters and declining precipitation patterns have had a negative impact on agriculture and livestock. These influences have been incompatible with indigenous knowledge and the cyclical agrarian schedule and have prepared the ground for people's exodus. With a population of 3843 inhabitants in 1104 households ( 1.49 persons per $\mathrm{km}^{2}$ ), the population statistics of the Upper Mustang region show a constant decline at the decadal ratio of 1.40 . The number of households is decreasing at a decadal ratio of 1.14 [6]. This population figure has a close relationship with the migration rate (19\%) from the mountain region to the plain areas of Nepal [22].

The study area - Lomanthang - is a rural municipality located in Upper Mustang. The inhabitants of Lomanthang are the indigenous Loba people. The total population of the Loba community is 569 with a female population of 293 and 276 males in 172 households in total. The household size is 3.30, which is lower than the national average of 4.9 persons. The dependent population's proportion is high. Around $18.6 \%$ of the total population are children, and the proportion of people aged above 80 years is $9.7 \%$. As a unique example of Tibetan culture, the Loba people are followers of Tibetan Buddhism and are culturally and ethnically of Tibetan origin with close socio-economic, cultural, linguistic, geographical and historical affinity with Tibet [20]. The Loba livelihood is based on agropastoral sustenance. But the existing rangeland is inadequate for livestock because, due to overgrazing, most of the area is desolate and resembles a cold desert [19]. Low and unpredictable rainfall pattern, decline in soil moisture, decreasing humidity, shifting snowfall and increasing air temperature have led to a water crisis with an adverse effect on plants and animals' growth, agriculture and livelihood [17]. Due to the scarcity of water, rising temperatures and desertification in mountains, culturally rich Lobas, who depend on subsistence agriculture and livestock, have been forced to migrate to new places for a better life [21]. The changing climate has obligated Lobas inured to adaptation to traditional agropastoral livelihood; however, there are only few 
sources of information on climate change. About $32.5 \%$ information on climate change and its effects have been obtained from local people's own observation of climatic variations.

The Himalayan region of Nepal has been a hub for diverse research. Since the 1950s, the Himalayan region has been popular for tourism activities and tourism-related research. Most research on the Himalayan region has been focused on adventure tourism, local lifestyle, culture, religion, climate, ecology, agriculture, population history, and the structural aspects of the region. However, until now, there has been very limited anthropological research on climate inconsistency, the relationship between people and their livelihood, especially on understanding how local communities and their cultures experience climate inconsistency and deal with it. Researchers' attention to climate change adaptation lacks adequate emphasis on the local nature of adaptation to climate change [1]. Hence, the main objective of this paper is to appraise the changing climate, its impact and the diversified practices of agropastoral adaption by the indigenous Loba community of the Mustang district of Nepal.

Inspired by the anthropological doctrines of the interpretivist and positivist traditions labelled as 'a combination of the anthropological and the survey method' [7], both qualitative and quantitative approaches were used in this study. For primary data collection, the fieldwork was conducted from May 11 to June 10, 2019. Using the quantitative survey method, first, listing was done among the Loba households dependent on agropastoral subsistence to classify the eligible households, and 105 such households were acknowledged. From these, per purposive sampling, 80 households were selected as the sample of the study. The total population of these 80 households is 261 (female 135 and male 126). From these 80 households, one household head was selected from each for the study on the rationale that, as aged, they are sensibly familiar with the changing climate.

Beyond the survey method that was applied for collecting quantitative information on the climate change effect on local livelihood, qualitative ethnographic information was collected through observations, interviews and case studies on individual understanding, appraisal and adaptation experiences in the agropastoral production system. There were numerous challenges and complications in collecting data in a remote mountainous region as Lomanthang. The initial challenge was travelling in remote rugged mountains in tough climatic conditions. The succeeding challenge was to convince the inhabitants to share their everyday experiences on climate change. Ethical authorization in the form of verbal consent was obtained from each respondent before data collection. 


\section{DIVERSIFIED PRACTICES OF ADAPTATION}

Unlike the highly specialized practice of modern standardized agriculture, traditional mountain farming systems are characterized by diversified practices [14]. Diversification is a rational strategy of risk reduction for the mountain people [15]. The diversified mountain farming system encompasses cultivated fields, livestock, woodland, pasture, and beyond all, a highly specialized community-based human labour management system. Mountain farming systems are also very flexible in response to environmental as well as socio-economic changes [3]. With limited arable land and a short crop growing season, the Trans-Himalayan mountain region Lomanthang is typified by high levels of risk and vulnerability associated with geographical conditions causing the lowest of agricultural and livestock production per unit. In a flexible community, the unity of the agropastoral production system, subsistence agriculture and livestock are the main bases of Loba economy and livelihood vigorously associated with factors like accessibility of irrigation water, seed, manure, soil nutrients, human labour, livestock, pastureland, landholding, food consumption pattern, seasonal migration, goods exchange system and distribution of resources. Recently, the traditional agropastoral system has incorporated some modern technologies (threshing machines, tractors) to cope with the changing climate. Owing to premature growth of crops, aridness, and insufficiency of irrigation water, Lobas are cultivating different varieties of vegetables and fruits. The nexus of the altering environment and the agriculture system can be comprehended via human ecological analysis that focuses not only on one aspect but on holism in an all-inclusive way. Such correlation can be observed in the relations between the humans and other animals, plants and their habitats [12].

The Nyéléni declaration of 2007 states that food sovereignty is the right of people to healthy and culturally appropriate food produced through ecologically sound and sustainable methods, and their right to define their own food and agriculture systems [16]. Agricultural production, consumption, conservation and sustainable use of local varieties embedded in Loba food sovereignty is destined to produce, control, distribute, and consume food encompassing the rights to healthy and culturally appropriate foodstuff. Indigenously produced buckwheat, naked barley, potatoes, grain, mustard, etc. have sociocultural, nutritional, commercial and medicinal value. Grain, meat, milk and butter making up a large proportion of the diet are used to satisfy the family's main nutritional necessities. The prevailing local belief is that meat generates heat to cope with severe cold. Tsampa (barley flour) is widely used with buttered tea and chhurpi (dried cheese) as a medicine for pregnant women, the sick, the old and children. 
Considering the biological and cultural significance of food, the crops production archetype is a medium of social interaction - production, processing, preparation and consumption are community-based. Young males and females, the elderly, children, relatives and neighbours equally participate during cultivation, harvesting, processing and consumption. The agriculture season begins with a ritual called Sakaluka. In this sacrament, women plough cultivable land to appease the Snake God and to seek blessings for good weather and harvest. Ethnographically, Sakaluka is a shared action of social, cultural, spiritual and material magnitudes to prevent life-threatening weather events and to express community solidarity, bringing them together, confirming collectivism, promoting unity to cope and resolve the natural phenomena.

Crops' worth differs according to household demand, consumption pattern and livestock population. Yaks, naks, mountain sheep, goats, horses, and mules are part of pastoral livelihood used for nutritious food items as milk, yogurt, fat, butter, cheese, and meat as well as for manure and fuel. Prior to the development of modern transportation, yaks, horses and mules were the popular transportation medium. But with modernization, goods are transported by trucks and tractors, which has led to a decline in the number of livestock. Peas and wheat were the popular fodder items to feed livestock, but with the diminishing numbers of livestock, there is little demand of peas and wheat. The decision by the Chinese government to proscribe the age-old tradition of free access for grazing Lobas' livestock in Tibet has led to a further decline in the number of livestock. Instead of peas and wheat, potatoes and buckwheat are now the valued crops for export. Increasing temperature, fluctuations in precipitation patterns and paucity of irrigation water have reduced agricultural productivity of many crops. Waning rainfall has caused a decline in crop production, crop failure, and frequent attacks by insects. About $40 \%$ of Loba farmers have experienced a decline in their agropastoral production, which has had serious ramifications on cultural rituals and festivals. Food security was a major concern for about $52 \%$ of households. Scarcity of irrigation water has led to the increase of fallow land by $16 \%$ and decrease of grassland by $12 \%$. Declining crop production has led to a halt in the export of foodstuffs to Tibet. In a changing climate, with declining agricultural production and alternative income sources from tourism, the once self-reliant Lobas nowadays consume food items imported from India and Tibet, which has led to the decline in the value of indigenous crops. Imported rice has become a conspicuous food that has threatened the indigenously produced crops consumption pattern, which is a course of action towards losing traditional food sovereignty. 
The indigenous food distribution system has altered amidst the availability of imported food items, changing food habits, changes in economic value of different varieties of grains and the livestock production pattern. Nowadays, high mountain areas are increasingly visited by tourists [26]. Since the advent of tourism in Lomanthang in 1992, most indigenous food items are served to visitors (tourists). Loba heritage and capacity to produce healthy, high-quality food has been threatened and destabilized by economic liberalization, market capitalism and the altering climate. Food autonomy had given the indigenous Lobas the sanguinity and authority to preserve, recuperate and build on their indigenous food producing capacity and aptitude for the collective survival of the community. The tradition of bartering local crops for Tibetan salt has halted due to the decline in crops production and the availability of imported salt in the market. Hence, the Lobas have lost their ancient sovereignty depending on salt and grain barter trade.

The traditional fraternal polyandry (a woman married to several brothers of the same family) had facilitated and organized the Loba family and had supported cultivation and familial barter business. Polyandrous marriage had been a tool for managing the inherited property, livestock, grazing paddock and forest that had assisted in keeping the paternal property indivisible, maintaining agricultural sustainability and, hence, keeping the concept of food sovereignty vibrant. With diminishing polyandry, the whole sociocultural and economic fabric of the family life is altering. The forces eroding polyandry are modernization, increasing education, weakening social bonds, alternative income sources from tourism, and the changing lifestyle.

Productivity depends upon the weather conditions and insects' attacks. Productivity is also sensitive to frost and hail [4]. Manifestations of nature and the marginal geo-climatic location have confronted the Loba indigenous knowledge on weather and, thus, threatened the local production system. Despite all attempts, the crop output is not high. With poor soil quality, inadequate manure and water, more seeds are needed, and harvest proportion is also low. The seed has to be highly concentrated while broadcasting. Due to unusually cold winters, the sprouting of seed is very slow and low. Further, the seeds are destroyed by birds, rats and bugs. Organic pesticide was the indigenous preference, but the emergence of new pests on crops and decline in routine crops has forced the Loba farmers to use chemical pesticides on crops and vegetables. Mounting summer temperature has obligated them to follow yearly crop rotation to improve soil fertility and to avoid insects. Their responses and adaptation consist in repetitive sequence of preplanned strategic adjustments. Based on their indigenous expectations on climate, Loba farmers proceed to carry out 
agricultural practices based on a well-established crop rotation pattern called Kar-Nak. If wheat or naked barley is grown in Kar (the previous year), Nak crops - peas, mustard, or buckwheat - are cultivated the next year.

In the process of climatic adaptation, several green vegetables are nurtured and consumed at present, which was improbable few decades ago. Until a few years back, asparagus was grown at the altitude of 2200 meters, but now it is grown at an altitude of 3750 meters. Locally grown courgettes, cauliflower, cabbage, carrots, coriander, string beans, beans, and turnips are the main vegetables. Vegetables like cauliflower, cabbages, string beans, spinach, which grow at lower elevations with higher temperatures, are growing faster. Until 2009 , courgettes could be grown only in the greenhouse, but now they are grown outside. Cucumbers, chili, tomatoes, and bitter gourds are grown in greenhouses. The varieties of crops which were previously grown during winter are now cultivated during the summer season as an upshot of climate change adaptation. Until a few years ago, it took two years to grow big-sized onions, but now they grow outside the greenhouse within a year. Previously, apples were not grown, but nowadays high-quality apples are grown in orchards by using chemical fertilizers. Apricots, peaches, plums, pears, walnuts, and grapes are grown, widely consumed locally and sold to tourist resorts. Less rainfall and raising temperature have resulted in smaller crop production, crop failures, and more insects' attacks but have had a positive effect on vegetable and fruit farming.

The Loba traditional custom of lakti-chikula, a habitual form of labour group rotation, is under pressure owing to the dearth of human resources. Under this customary system of labour exchange, labourers are mobilized in the field to plough, collect manure, make canals, etc. Seed broadcasting is done by a well experienced person of a lakti-chikula group organized in a cluster, and they work in each individual household who participates in the group. With adequate time arrangement, this group goes turn by turn to each household. But currently, due to the acute shortage of labourers during the harvest season, wage labourers are hired from other districts of Nepal. Because of Lobas' rapid permanent migration to several cities of Nepal as they are afraid of becoming climate refugees, the wages of hired labourers are escalating, which makes it more expensive for the farmers to cultivate crops. It is economical to purchase foodstuff rather than to pay wages to farm labourers. This predilection is challenging the agropastoral practices and the food sovereignty.

Despite numerous challenges in a changing climate, the Lobas have continued practicing agropastoralism as their traditional occupational identity, holding ancestral land and livestock as their inherited property by seeking 
gender participation for keeping the agropastoral system of subsistence intact. Amid patriarchal norms, gender participation in agriculture and livestock is imperative for Lobas to preserve their agropastoral livelihood system. However, women bear a greater burden, although both men and women are affected by and vulnerable to climate change and global warming [24]. With their heavy work burden, women have higher social status in the family and community. Women are mostly responsible for the household chores, including the management of drinking water. With drying water sources, management of drinking water and irrigation has become convoluted for the elderly females and males. Due to the nature of public goods and the lack of properly defined rights for their use, the management of irrigation water is a complex issue [6]. Under the customary norms of collective water resource management, the village headmanship system is accountable for the fair distribution of water. The village head takes the responsibility for mobilizing the fraternities, kin groups and lineage for the mandatory labour required for water management. Labour contribution for irrigation canal maintenance is fixed proportionately to the land holding and seeds required for cultivable land. Households with little or ample land are obligated to contribute proportionally to the maintenance of the irrigation canal. Even landless households have to contribute a single day of labour. This self-organized system of community management of water resources has increased equal access to drinking and irrigation water where government services are lacking. The leadership role of the headman, agreed vision and collective action have sustained the community-managed water system. This system represents the indigenous method of water resource management, which is the indicator of indigenous affinity, community headmanship, the institution of polyandry, assets bequest, land access and, most importantly, the agropastoral system that has created the indigenously managed irrigation system contrived and nurtured by the social arrangement. However, the diminishing tradition of polyandry and the fragmentation of paternal landholdings has threatened the traditional water management practices. Further, the glacial lake outburst flood has led to the erosion of riverbeds. Irrigation along with agriculture has been affected not only by global warming and extreme weather events, but also by the altering sociocultural institutions as polyandry, modernization, modern transportation facilities, permanent migration, tourism and the Chinese government's policy. There has been a grave impact of Chinese annexation of Tibet in this part of the world. 


\section{PERIODIC RELOCATION AS AN ADAPTATIVE RESPONSE}

Owing to high rugged mountains, snowfall, extreme cold and hardships in the freezing winter, seasonal relocation (migration) during winter (NovemberFebruary) is an indigenous practice of the Loba community that has helped them mobilize resources other than their cultivated field. This migration is imperative from the religious, economic, and social perspective and has a prodigious impact on agropastoral production and food consumption. Loba families migrate during winter after the end of the harvest season. They trade local craft items and herbal medicines in the cities of Nepal and India, visit relatives, pay pilgrimage to religious sites, treat sick family members and relatives. Since livestock is a significant link in the agropastoral farming system, livestock is stall-fed with leaves, grass and crop waste during the seasonal migration by the few elderly people remaining at home.

During the short migratory period of cold months, food is accumulated at home in the absence of most family members. During this wandering period, Lobas earn cash by trading goods and services which are used to buy items such as foodstuff, drinks, and attire while coming back home. Seasonal migration during the winter season is a unique indigenous strategy to muddle through hardship with cold, food and other necessary items and have insinuations on the old-fashioned joint family structure and polyandry. Womenfolk play a fundamental role in vendoring goods during the wandering period in the plain areas. But the alterations in traditional polyandrous marriage and fragmenting family relationships (leading to monogamous nuclear families) have caused severe consequences on resources mobilization in agriculture, livestock, and human labour. Amid the robustness of environmental stressors, the seasonal migration of Lobas is a survival strategy that fulfils their needs and enables them to live their life amidst hardships. In a warming world with altering sociocultural institutions, such unique migration or repositioning may alter or fade away in the long run. But, with far-reaching ramifications for those who stay behind, this migration is an adaptive response to make maximum use of natural assets, ensuring food safety and reinforcing the economic and social setup of the mountain ecosystem.

\section{CONCLUSION}

The upshots of climate change and altering sociocultural institutions have generated different kinds of menaces to and prospects for agropastoral livelihood, food sovereignty, economy, culture and indigenous acquaintances in 
relation to native environment. The fragile geophysical location and marginalization of indigenous people, changes in lifestyle and institutions have accelerated the process of climatic alteration that has brought about restructuring of the traditional agropastoral livelihood with diversified practices as adaptive responses to climate change. The headship role of the community headman, shared vision and community action have facilitated agropastoral adaptation in this part of the world. As climate change is related to the human-environment nexus, managing of climate-related risks in geographically relegated remote regions necessitates innovative technologies to adjust with diversified livelihood practices, skills, information, risk analysis and water saving practices to obviate the intimidation of concealed hunger and the climate émigré quandary. There is a need to comprehend the changes that have occurred, adapt to them, and make the most of the innovative opportunities.

From the anthropological standpoint, the effects of climate change do not only concern the community's capacity to adapt and to exercise diversified practices flexibly; they are furthermore related to how the sociocultural institutions accommodate to change. Such adjustments necessitate a managementsmart adroitness or repositioning of culture-nature relationships that not only authenticate indigenous worldviews but also work to maintain and preserve local landscapes, culture, traditions and quintessence by expanding adaptive capacity closely to its sensible parameters. As community involvement and know-how are the secrets which ensure the success of such actions, policy interventions at the civic level form a prerequisite.

\section{REFERENCES}

1. Agrawal A., Kononen M., Perrin N. (2009). The role of local institutions in adaptation to climate change. Social Development Notes, No. 113. Washington, DC: World Bank. https://openknowledge.worldbank.org/handle/10986/11145

2. Barnett T.P., Adam J.C., Lettenmaier D.P. (2005). Potential impacts of a warming climate on water availability in snow-dominated regions. Nature, 438, 303-309. https://doi.org/10.1038/nature04141

3. Bishop N.H. (1998). Himalayan herders. Orlando: Harcourt Brace \& Company.

4. Brown M.E., Antle J.M., Backlund P. (2015). Climate change, global food security, and U.S. food system. https://www.usda.gov/sites/default/files/documents/ FullAssessment.pdf. https://doi.org/10.7930/J0862DC7

5. CBS. National Population Census (2012). Household and Population by Sex, Ward Level: Mustang. Kathmandu: Central Bureau of Statistics. 
6. Chaulane P. (2009). Water, Wealth and Power: A Case Study from Upper Mustang of Nepal. Occasional Papers in Sociology and Anthropology, 11, 104-125. https://doi.org/10.3126/opsa.v11i0.3033

7. Chhetri R.B. (1992). Adaptation of Tibetan refugees in Pokhara, Nepal: A study on persistence and change. $\mathrm{PhD}$ dissertation submitted to the University of Hawaii.

8. Cook J. (2014). Skeptical Science, It's not bad. http//skepticalscience.com global-warming-positives-negatives

9. Dankelman I. (2002). Climate change: learning from gender analysis and women's experiences of organizing for sustainable development. In: Gender, Development and Climate Change. Eds. Masika, Rachel. London: Oxfam, 21-29.

10. Dessler A.E., Parson E.A. (2006). The science and politics of global climate change: A guide to the debate. Cambridge: Cambridge University Press.

11. Government of Nepal, Ministry of Environment. (2010). National Programme of Action (NAPA) to Climate Change. Kathmandu, 8-17.

12. Kassam K.A.S. (2001). Passing on the knowledge: Mapping human ecology in Wainwright. University of Calgary. http://dx.doi.org/10.11575/PRISM/35443

13. Kates R.W. (2000). Cautionary tales: adaptation and global poor. Climatic Change, 45(1), 5-17. https://doi.org/10.1023/A:1005672413880

14. MacDonald K.I. (1998). Rationality, representation, and the risk mediating characteristics of a Karakoram mountain farming system. Human Ecology, 26(2), 287-321. https://doi.org/10.1023/A:1018723024702

15. Mishra C., Prins H.H.T, Van Wieren S.E. (2003). Diversity, risk mediation, and change in a Trans-Himalayan agro-pastoral system. Human Ecology, 31(4), 595-609. https://doi.org/10.1023/B:HUEC.0000005515.91576.8f

16. Nyeleni Organization. (2007). Nyeleni declaration. http://nyeleni.org/IMG/pdf/ DeclNyeleni-en.pdf

17. Prasain S. (2018). Climate change adaptation measure on agricultural communities of Dhye in Upper Mustang, Nepal. Climatic Change, 148, 279-291. https://doi.org/10.1007/s10584-018-2187-1

18. Rodenberg B. (2009). Climate change adaptation from a gender perspective: A cross-cutting analysis of development-policy instruments. German Development Institute, 7.

19. Schaller G.B., Gu B. (1994). Comparative ecology of ungulates in the Aru Basin of Northwest Tibet. National Geographic Research and Exploration, 10, 266-293.

20. Selter E. (2007). Upper Mustang: Cultural heritage of Lo Tso Dhun. UNESCO, Kathmandu. https://books.google.com.np/books?id=t2skOgAACAAJ

21. Shahi P. (2009). Climate change hits Upper Mustang, entire village moving to better area. Kathmandu, Sep. 28, The Kathmandu Post Daily, 8. 
22. Suwal B.R. (2014). Internal migration in Nepal. Population Monograph of Nepal. Kathmandu: Central Bureau of Statistics, 1, 241.

23. United Nations Development Programme (UNDP). (2008). Fighting climate change: human solidarity in a divided world. New York: UN Plaza, 28-31.

24. United Nations Development Programme (UNDP). (2010). The Contribution of UNDP-GEF Adaptation Initiatives Towards MDG3. New York: UNDP-GEF, 3-6.

25. Upadhyay P. (2016). Climate Change as Ecological Colonialism: Dilemma of Innocent Victims. Himalayan Journal of Sociology and Anthropology, 7, 111-140. https://doi.org/10.3126/hjsa.v7i0.17153

26. Welling J.T., Árnason P., Ólafsdottír R. (2015). Glacier tourism: A scoping review. Tourism Geographies, 17(5), 635-662.

https://doi.org/10.1080/14616688.2015.1084529

\section{Address for correspondence:}

Prakash Upadhyay

Department of Anthropology

Tribhuvan University

Prithvi Narayan Campus, Pokhara, Gandaki Province, Nepal

E-mail: prak-socio@hotmail.com 